\title{
Novos paradigmas da produção musical independente no pós-internet
}

GALLETTA, Thiago. Cena musical paulistana dos anos 2010: a "música brasileira" depois da internet. São Paulo: Annablume/FAPESP, 2016.

Renato Gonçalves ${ }^{1}$

A internet revolucionou a vida contemporânea e ainda estamos tentando entender seus reflexos - o uso do gerúndio, para abordar o assunto, é quase inevitável. Depois de seu advento, diversas práxis sociais, culturais e comunicacionais têm sido modificadas. Se a internet não as alterou completamente, o que costuma ser uma afirmação corriqueira entre os entusiastas das tecnologias, pelo menos ela tem oferecido novas possibilidades para velhas práticas. Apostando na percepção de que algo também foi ampliado no que diz respeito à indústria fonográfica, o trabalho de Thiago Galletta, Cena musical paulistana dos anos 2010, busca identificar e documentar as transformações pós-internet na "música brasileira".

O objetivo da investigação de Galletta é claro: realizar um mapeamento da chamada "cena musical paulistana dos anos 2010", buscando compreender quais fatores nos levam à ideia de que se configurou uma nova cena cultural nos últimos anos na cidade de São Paulo. Por se tratar de um trabalho que tem

\footnotetext{
1 Doutorando em Ciências da Comunicação pela ECA-USP. Mestre em Culturas Brasileiras pelo IEB-USP. Membro do GESC3 (Grupo de Estudos Semióticos em Comunicação, Cultura e Consumo). Contato: r.goncalves.f@ gmail.com.
} 
o olhar sociológico como ponto de partida, o autor busca a todo o momento matizar os termos "artista independente" e "cena paulistana", desenhando o que se apresenta como um campo de disputas simbólicas com posições mais ou menos definidas em torno de tais rótulos. Para essa tarefa, a pesquisa mobiliza falas de artistas e demais agentes, como jornalistas e produtores, além de resgatar, em uma perspectiva ampla, fatores de base que estivessem ligados, direta ou indiretamete, à formação dessa cena.

Na primeira das duas partes principais do livro, "Música e internet: a emergência de um novo mundo para a produção musical independente brasileira", há um esforço para se estabelecer ligações entre as estruturas industriais e comunicacionais e a produção independente na experiência brasileira.

Ser um artista independente no Brasil não é algo novo e, por isso, no primeiro capítulo, "A produção independente brasileira antes da internet", retoma-se a dimensão histórica do termo. Embora seja difícil precisar qual teria sido a primeira iniciativa independente no Brasil, o autor destaca o LP Feito em casa (1977), de Antônio Adolfo, gravado, prensado e comercializado de forma totalmente autônoma já na década de 1970. A partir da década de 80, a produção independente ganha fôlego com Arrigo Barnabé, Itamar Assumpção, Premeditando o Breque e Grupo Rumo, artistas e bandas da chamada Vanguarda Paulistana, que obtiveram certo reconhecimento de público nos circuitos alternativos de shows.

No capítulo 2, "Música e internet: a emergência de um novo mundo para a produção independente brasileira", Galletta adentra a seara da internet para compreender os seus impactos na produção, circulação e consumo de música. Ainda que seja reconhecido o caráter emergente dessas transformações, o autor consegue identificar e delinear, em ordem cronológica, ao menos quatro etapas das relações entre a internet e a música no Brasil.

A primeira fase (I), que vai de 1995 a 1998, foi marcada pelo início de novas práticas sociais mediadas pela internet. $\mathrm{O} e$-mail, as primeiras plataformas de mensagem instantânea (como o ICQ e o MSN) e a possibilidade de criação de sites tornaram-se 
importantes ferramentas para os artistas, agilizando a articulação necessária para a realização de shows e das demais rotinas da esfera da produção executiva.

Em um segundo momento (II), as plataformas de compartilhamento de música e as novas comunidades virtuais iniciaram uma longa disputa travada pelas grandes gravadoras contra as novas ferramentas tecnológicas. Entre 1998 e 2006, pode ser observado que o crescimento vertiginoso de softwares P2P, como o Napster, gerou novas formas de relacionamento entre os consumidores de música e os registros fonográficos, que agora não mais somente poderiam ser obtidos no formato físico e armazenados em coleções, mas também compactados no formato MP3 e organizados em pastas virtuais. Thiago Galletta aponta, nesse momento, duas novas tipologias de consumo musical: o público passivo e o público interessado. Grosso modo, o primeiro público, o passivo, seria atingido pelos produtos fonográficos difundidos nos meios tradicionais e mainstream de veiculação, como a televisão e o rádio; já o segundo, o interessado, chegaria aos registros a partir de interesses próprios e pesquisas individuais que se dariam através de circuitos virtuais e alternativos, composto por blogs e comunidades virtuais. Galletta mais a frente evidenciará que o público interessado será um dos principais articuladores para a nova cena.

A terceira fase (III), que vai de 2006 a 2009, é marcada pelo nascimento, no bojo da internet, de uma comunidade de gravadoras e artistas independentes. A partir de redes sociais, como Orkut e MySpace, esta última voltada exclusivamente para a divulgação musical, artistas de todo o Brasil começaram a estabelecer conexões com pequenas gravadoras e a alcançar e formatar uma massa de público interessado sem que fosse necessário fazer uso dos intermediários tradicionais, isto é, sem a necessidade de integrar meios massivos de promoção e publicidade. Além disso, destaca o autor, a popularização da banda larga no Brasil foi fundamental para o crescimento do número de usuários de internet e a melhora da velocidade de conexão que permitia, agora, uma maior adesão às plataformas 
de streaming de vídeos, como o YouTube, que logo se tornariam um grande repositório de registros audiovisuais históricos e contemporâneos. A respeito deste último aspecto, Galletta aponta que o acesso a conteúdos em escala global vem possibilitando o acréscimo de repertório cultural do público e dos próprios artistas, como no caso do músico Thiago França, que entrou em contato com o afrobeat através de vídeos no YouTube e, desde então, tem incorporado elementos dessa manifestação musical de origem afriacana em suas composições.

Considerada como sendo a última fase (IV), iniciada em 2009, o momento atual é de crescimento de redes sociais, como Facebook e Twitter, e de utilização dessas plataformas como espaços importantes de visibilidade midiática. Nesse processo, pessoa física e figura pública se fundem e se confundem, e o artista pode se relacionar tanto com seus pares quanto com os demais agentes do circuito da cena musical, como jornalistas, blogueiros, produtores e, certamente, o público, borrando todas as fronteiras que outrora existiam. Observando a gestualidade do "curtir" e do "compartilhar", o pesquisador afirma que, hoje, há "um movimento de constantes trocas, apropriações e reapropriações" (p. 92), o que justificará, em parte, a articulação, a coesão e a união de artistas independentes na cena paulistana.

Encerrada a primeira parte dolivro, voltada para as complexas relações entre produção, circulação e consumo independentes e as evoluções da internet, Thiago Galletta direciona seu olhar para a "cena musical paulistana dos anos 2010". No capítulo 3, o pesquisador elenca três dos principais aspectos que se destacariam em um contexto geral para além das questões regionais.

O primeiro procedimento da pesquisa, nessa etapa, foi o dimensionamento da produção independente em relação à produção fonográfica nacional. Produzir paralalemente ao grande mercado trouxe novos significados para algumas práxis da indústria. Gravar um disco, para os artistas independentes, passa a não ter mais como finalidade o objeto disco em si: torna-se um meio para gerar pauta na mídia e ajudar a fechar uma agenda de shows pelo país. Os estilos musicais, outrora 
rótulos nas prateleiras do mercado, não são mais seguidos à risca, o que propicia experimentações estéticas e desestabiliza as narrativas de uma possível "tradição musical", construída e alimentada, ao longo das décadas, pela própria indústria. As carreiras são administradas com certo grau de dificuldade, pois agora é demandado do artista um conhecimento muito mais completo do mercado. E, por fim, a produção independente aumenta vertiginosamente o número de lançamentos anuais, correspondendo a $90 \%$ desse montante, como aponta Mauricio Tagliari, proprietário da gravadora independente YBMusic, em fala citada por Galletta.

O segundo e último ponto destacado do contexto geral da produção indepedente é a relevância dos editais, das Leis de Incentivo à Cultura e dos circuitos independentes de fomento à produção artística. Sendo uma discussão extensa (devido à variedade de possibilidades), imprecisa (pois são de alta volatibilidade as variáveis externas a ela) e, por vezes, polêmica (por serem muitas as visões e crenças a respeito do tema), é importante destacar que a música, dentre todas as artes, tem tido um lugar privilegiado em políticas públicas e iniciativas cooperativistas, sendo essas grandes forças propulsoras para a realização de discos e shows no Brasil nos últimos anos.

O breve capítulo 4, "Representações possíveis: a cena enquanto fenômeno artístico e cultural", prepara a extensa discussão do capítulo 5, "Especificidade de São Paulo-SP [...]". Matizando o termo "cena musical", Galletta vai localizar, a partir das falas de alguns dos agentes mais relevantes da "cena musical paulistana", impressões e percepções sobre o então agora. Por mais que não haja um consenso sobre esse fenômeno atual, que é classificado tanto como um "momento" quanto como indícios de uma nova "geração", reconhece-se que a cena é estabelecida a partir de uma nova configuração. Nessa direção, São Paulo parece ser um dos espaços mais pertinentes para a realização de algo que se propõe enquanto novidade.

É de comum acordo que São Paulo, hoje, concentra a maior parte dos artistas independentes do Brasil. Porém, quais 
bases materiais e simbólicas sustentam esse fenômeno? O autor, buscando responder a questão, elenca cinco dos principais aspectos: (1) condição econômica privilegiada dentro do país; (2) existência de um polo econômico-cultural relevante; (3) concentração de canais midiáticos; (4) presença de um território urbano alternativo; e (5) acesso facilitado às tecnologias de produção e divulgação. Tendo deixado claro essas especificidades, o pesquisador caminha para o final do livro, buscando evidenciar algumas das nuances da experiência musical independente na cidade que a caracterizaria como uma possível "nova cena musical paulistana".

Uma vez que o disco deixou de ser a finalidade do trabalho do artista, como vimos anteriormente, os circuitos de casas de espetáculos em São Paulo são vitais para a manutenção dessa cena. Casas de pequeno e médio porte, como a Casa de Francisca, na região central da cidade, têm sido relevantes para a apresentação de novos artistas e projetos e, consequentemente, para a formação de público. A rede SESC-SP, instituição privada associada à FECOMERCIO, também tem se mostrado um circuito importante para a cena independente, uma vez que, além de disponibilizar seus teatros, distruídos em 34 unidades na capital e no interior do Estado, oferece uma remuneração considerada justa aos artistas.

Estando alheios dos grandes meios de produção, circulação e consumo, os artistas independentes de São Paulo acabam por estabelecer, de forma orgânica, redes entre os agentes dessa cena. Dessa realidade, ocorre uma constante movimentação entre instrumentistas, compositores e intérpretes, que acabam circulando por entre projetos e bandas, tal como Galletta vai destacar na complexa e, por vezes, confusa trama de interconexões que nos serve de exemplo. Nela é possível perce-ber que um mesmo artista, quase sempre, chega a participar de dois ou mais projetos simultaneamente. A título de exemplificação, a intérprete Juçara Marçal fez parte, nos últimos cinco anos, da banda Metá Metá e do projeto "Sambas do absurdo", além de ter desenvolvido um disco solo, Encarnado 
(2014), no qual também estão presentes instrumentistas dos dois projetos mencionados. Tal variedade permitirá que o artista possa "viver de música" - o que muitas vezes é considerado como o "sucesso" de um artista independente - e, a longo prazo, acabará criando uma sonoridade própria e comum a todos esses projetos.

Por fim, há o relacionamento com os meios tradicionais e alternativos de mídia que, uma vez concentrados na cidade de São Paulo, têm desenvolvido projetos e programas especiais para dar vazão e visibilidade à cena paulistana. São dignas de destaque as iniciativas das jornalistas Roberta Martinelli, à frente do programa Cultura livre, da TV Cultura, e Patrícia Palumbo, que, mais recentemente, lançou a Rádio Vozes, uma rádio on-line voltada exclusivamente para a programação brasileira. Através do filtro midiático, a nova cena paulistana vai chegando ao público com ares de novidade e tendo seu rótulo fortalecido a partir do reconhecimento midiático.

O capítulo 6, que encerra o trabalho, "Que som é esse? Geração fora da prateleira $[\ldots]$ ", põe às claras o embate terminológico entre "MPB" e "música brasileira". Se a primeira é considerada pelos agentes da cena paulistana como sendo um rótulo construído pela indústria fonográfica que, de certa forma, engessa o material artístico, a segunda é muito mais ampla e abarca todas as possibilidades estéticas dentro da realidade contemporânea. Sem se alongar muito nessa discussão, Galletta aponta para novos e possíveis desdobramentos de sua pesquisa.

Como evidenciamos já de início, o livro trata de um processo ainda em acontencimento. As atuais plataformas de streaming, como Spotify e Deezer, e as constantes reformulações dos algoritmos das redes sociais e do investimento pago dentro delas, por exemplo, ficaram de fora, o que indica que os reflexos das evoluções tecnológicas nas esferas de produção, circulação e consumo de música deverão ser constantemente dimensionados. Contudo, a discussão iniciada por Thiago Galletta se mostra relevante a partir do momento em que o pesquisador traça parâmetros para a análise, demonstrando que as questões vão muito além da própria internet. 